\title{
Analysis on the Feminism under the Perspective of Anthropology
}

\author{
Linyu Wang \\ College of Chinese Language and Literature, Hunan University, Changsha 410001, China. \\ 18508412701@163.com
}

\begin{abstract}
Feminism anthropology which is a discipline that combine feminism and anthropology is a kind of cultural anthropology research orientation. In the early of 1970s, with the rise and development of feminism and female disciplinary research, female anthropology gradually comes into the public view, and it is embodied in the research of women's physiology, social and cultural gender, gender relations, women's social status and power etc. Feminist anthropologists usually start from the concept of gender, actively advocate writing feminist ethnography, arousing women's self-consciousness, and reshaping their body and mind. Based on the feminist criticism, this paper discusses the feminist connotation in the field of anthropology by combining concrete examples.
\end{abstract}

Keywords: Anthropology; feminism; gender; ethnography; subjectivity reflection.

\section{Introduction}

Feminist criticism was born in Europe and America in the late 1960s and early 70's, which is the result of the Western feminist campaign extending to the literature and even the cultural field, and so it has a more obvious cultural and political tendency. From the perspective of the female, it's trying to awaken women's sense of independence relative to men's, criticize the behavior in the patriarchal society, such as distorted female image and deprived women discourse rights, and laid the foundation for women to fight for their independence and right.

Along with the integration of various humanities disciplines, using the anthropological theories and methods to study the women's problem not only broaden the study of feminist criticism, but also make anthropology reflect the female "no voice" phenomenon of previous ethnographic study and the oppression and distortion of the male dominated thought. Through excavating a large number of pictures which describe women's living, feminist anthropologists bring the female gender that is being neglected previously into the human activities, and give them equal and unique value. In addition, these anthropologists also focuses on the effects of human history, economic, cultural and social factors on gender differences and relationships, but this time they abandoned the previous objective view, standing in the point of view of women to study the women's social status and power. However, this doesn't mean that to pass wantonly belittle male inherent in the subject position to promote women's self-awareness, but by discussing about women's topic, they adhere to the view of female to seek their cultural, social, academic concern. The representative female anthropologists include Margaret Meade, Ruth Benedict and so on. They regard the experience of women as a unique direction of anthropology research, and made a contribution to this emerging theoretical system and methods.

\section{Gender Perspective in Anthropology}

"Gender" is just a neutral word without any color. Since ancient times, people have followed it that the men and women have different labor roles in the society, that is, men go out to work while women look after the house. But after the rise of the feminist campaign which women revolt against oppression and fight for the rights of equality and freedom, people began to concern about gender differences, gender relationships and the function of gender in the field of human culture, history and life. So the "gender study" has extraordinary significance. Feminist anthropologists often attack the phenomenon of oppression of women in the patriarchal culture through the "gender" sword, and advocate female self-consciousness. 
Many facts show that since the formation of the patriarchal clan system, men become the core of social and family, they have the right to dominate the family members and property, while women are often regarded as the "secondary", as men's accessories. Back to one's roots, this phenomenon is still an unequal status of men and women in gender culture, which "differences" caused. Male and female have differences of physiology, psychology and culture, and the formation of natural physiological differences often leads to huge cultural gap between genders. With respect to the male culture, female culture is passive, being castrated, which just like translation compared to the original is insignificant, Third World countries' cultural compared to which in the Anglo-Saxon countries must be backwardness and ignorance.

First, men and women are not replaceable in terms of their physiological and sexual attributes. Men are naturally more powerful than women, and this kind of power can be turned into a form of power to a certain extent. This is why many cases of rape are related to the matter that leaders do sexual harassment to their subordinates. This sexual harassment is a violence that strong male power imposes on the female mind and body, and it can also be regarded as the strong gender oppress the weak gender. For example, in the Eve Ensler's "the Vagina Monologues", men use foul as an excuse to ban women taking the initiative to make the body responds to; they hate women engaged in sex work, but openly ravaged them. They make the female body wrapped airtight with a black cloth, and ready to discipline violators at any time. Therefore, in order to maintain their status, male tried to maintain this binary opposition mode, and keep the pressure and marginalization of women status.

Accordingly, from the perspective of culture and gender, the study of ethnic groups from the perspective of male feminism and the feminist perspective is the relationship between strong culture and weak culture to some extent. Xiaojia Zhang cited an example in the "female perspective ethnographic authenticity Thinking expression": Weiner went to Trobriand Islands to do fieldwork where Malinowski used to do fieldwork, found in the funeral that the woman in charge of economic exchange. But she did not find the woman-led economic activity recorded in Markov's writings, after investigation, she thinks women in the island play a decisive role in the stable social order [1]. The reason for this difference is nothing more than anthropology of gender inequality. We found that when male anthropologists conducting investigation, they don't investigate indigenous women, or show description of women in ethnography, but did not give analysis and comments, which made one-sided conclusions. A typical example is that in Emile, Durkheim "Primitive Classification", the author referred to female in the chapters of Australian tribes, the Zuni people, and the Soviet people, but only mentioned it when explain the inter-tribal marriage and clan relationship, and totemism, inheritance law which is mainly analyzed is also patrilineal inheritance.

However, the strong and weak position is very unscientific, and is not immutable. Helene Cixous mentioned that the woman's "better than men" features in his work "Laugh of the Medusa". In fact, women are more inclusive, transcendent even ambiguity groups, because although they are different from men, but they gave birth to the male, to create life, so they can understand the meaning of life and living more than men. Therefore, in the process of writing fieldwork and ethnography, there is also some voice that support dispels Anthropology male bias. Because in the traditional patriarchal society, male culture constraints women's characteristics, but generally lots of indigenous women know local customs, culture and production mechanism more than men. In early and middle twentieth Century, feminist anthropologists began to think through their own independent consciousness. "Women, culture and the society" which published in 1974 became feminist anthropology's first book; in 1975, the University of Michigan Department of Anthropology on women's Studies Seminar "toward an anthropology of women", these works marks the emergence of feminism anthropology [2]. Because the feminist anthropology is subject to the influence of feminism, so early feminist anthropology theory and early feminist view are similar, both of them focus on men-women and active-passive and other gender opposition, and defined the male and female separately. For example, men are the spokesman of social status, power and prestige, and women are mainly represented by the family labor and obedience. But men and women in gender culture is not the opposite, anthropologist in fieldwork concern ethnic or tribal overall, diverse cultural panorama, and not a single gender and one-sided mode of life. So it is not feasible to examine the two oppositely. 


\section{Subjectivity of Feminist Anthropologists and its Reflection}

As mentioned above, due to the cultural differences caused by gender differences in physiological, women were identified by society as a gender group which is not complete, and lack of autonomy. Therefore, in the field of culture, this kind of phenomenon in literary translation and writing methods ethnography and theoretical issues are often reflected.

\subsection{The Female Translator's Subjectivity in Literary Translation.}

Due to gender differences, both women and translation, is often denounced to the edge, so when the feminists is in the translation process, especially in the phase "Select Text", they usually incorporate screening initiative, which highlights the dominant position and independent experience of women and refute androcentric injustice against women; Furthermore, unlike the male translators, the female translators usually pay more attention to women's "body language", and were more concerned about the details of gender related discourse, showing the subjectivity of female translators through the word translation. By reading Eve Ensler's "the Vagina Monologues", we found that the subjectivity of female translators is different from male translators.

Eve Ensler's "the Vagina Monologues" translating into Chinese have two authoritative versions; one is Rongjun Yu translation version, another is professor Xiaoming Ai of Zhongshan University adapted version (Of course, there are a variety of colleges and universities, professional and private groups adapted version). Because the professor Xiaoming Ai is a Chinese contemporary feminist, so the lines exudes rebel against the patriarchal ideology, awakening of the female independent consciousness. In the original chapter "because he likes to see" has such a paragraph:

"Our self-hatred is only the internalized repression and hatred of patriarchal culture."

For the word "patriarchal", Rongjun Yu translated it as "power", while Xiaoming Ai translate it as "patriarchy" and Yu's version placed "power culture" in the end, while Ai's version, it emphasized that this patriarchal culture abetting us repression and hate ourselves.

In comparison, the male translators pay more attention to the author's macro feelings, and the female translators appear much more carefully and they are more concerned about the details of sensitive words. In fact, patriarchal means "parents" and "patriarch", but Ai's edition has a direct deepen it as "patriarchy." Since patriarchy, no matter from the physical or social perspective male plays a supporting role in family. At this time, women have lost the status as the primacy of wife and mother in the original matriarchal society, and gradually became to men's accessories. More importantly, the original playwright Eve Ensler is also a feminist, her original intention of creation is hope to enable women to understand and agree with the attributes of their own sex, and resolutely against gender violence by boldly telling vagina, because the understanding of the world of women in the patriarchal society whose individual experience are being deprived and body can't be respected in the long-term. So the same feminist Xiaoming Ai has more resonance in the translation: she saw the implicit words that the author writes to criticize the patriarchal culture on women's oppression and insult, showing the female's revived consciousness and women's cultural color.

\subsection{The Subjectivity of the Writing of the Ethnography.}

With the rise of feminist thought, some women anthropologists began to review some field survey scheme and method of writing in the previous classical ethnography, and look critically at the neglect and distortion of male anthropologist to female experiences.

"From the early days of the Ethnography born, they began using a method different from the conventional paradigm. In addition to innovation in ethnographic writing text, because of their gender characteristics, female anthropologists have the different research methods from male scholars in all aspects of the process of ethnographic knowledge production. This process includes fieldwork, analyzing and interpreting the data, and how to transform field material into text writing. In this several links, researchers with different gender will take the difference method, carries on the interaction with the research object."[3]

In other words, previous masculine ethnographic study emphasis on rational, objective, and women anthropologists trying to break this single writing mode, that is, in particular ethnography added the women's own experience in order to provide a new solution for Ethnography. For example, 
in the choice of topics, women will deliberately choose some feminine one that be ignored, and then combine with their own feelings to analyzes the cultural connotation behind the picture. Furthermore, when field trip to a tribe, female anthropologists treated the different ages or ethnic groups of women separately. Because of unique exquisite emotion, women are more flexible than men. In addition, male anthropologists may delete some does not conform to the fragment of the current social context in compiling stage, while women anthropologists will present different voice and culture in ethnography, especially that reflect the social history and life experience of the women. However, as the introduction of this article, the improvement of the subjectivity of women does not mean that the methods and content of the male fieldwork should be ignored.

When the Western feminist thoughts have developed to a certain stage, there is a radical feminism tendency, which is to promote the supremacy of the women's rights, and make the mark of women's rights in the text. Therefore, the British stream of consciousness female writer Virginia Woolf proposed the concept of "Androgyny" in his work "A Room of One"s Own", which to a certain extent can avoid the old model of binary opposition. In other words, regardless of the translation problem of feminist, or investigating and writing ethnographic, one should have a bisexual perspective and empathy ability [4]. If both genders are standing in their own gender position to think about the problem, then there will be a party to the supremacy of the trend. In this way, it is very difficult to have a complete description of the culture in the ethnography of anthropology. Therefore, women anthropologists should avoid the mistakes that the traditional male made in the process of field investigation in order to improve women's status and give full play to the subjective initiative, and at the same time to achieve a gender balance by fusing male anthropologists' beneficial theories and methods.

\section{Conclusion}

Feminist anthropologists managed to let the women which is a ignored gender group enter into people's vision by collecting a large number of painted pictures of women's life, and bring the personal experiences of women and the new theoretical approaches which is different from male's into the process of the field trips and ethnography writing. Through the analysis of anthropology from the gender perspective and the subjectivity of feminist anthropology in recent years, this paper shows that women anthropologists should actively safeguard women's rights to enhance the status of female subjectivity, and at the same time maintain the balance of male and female. Though feminist anthropology, this emerging discipline is still deficient on its methods, but what is undeniable is that it makes anthropology full of women's unique identity tension, and it also help the feminist criticism to find a new breakthrough in its own way.

\section{References}

[1]. Jessie. The anthropology of women's cultural and social construction and the post-modern research. Journal of Guangxi institute for nationalities (philosophy and social science edition). 2004. 26 (6).

[2]. Sukey. The female perspective of ethnography expression authenticity thinking "Fujian BBS" education (social sciences edition). 2010(10).

[3]. Sukey. The female experience of ethnographic text production way to research the influence of. Fudan University. 2012.

[4]. Virginia Woolf. A Room of one's own [J]. Chemistry - Occasions for Comment Poems. 1992. 